\title{
Overnutrition, ectopic lipid and the metabolic syndrome
}

\author{
Scott M Grundy
}

\section{Correspondence to}

Dr Scott M Grundy, Internal Medicine, UT Southwestsern Medical Center, Dallas, TX 75390-9052, USA; scott. grundy@utsouthwestern.edu

Accepted 29 April 2016 Published Online First 18 May 2016

Copyright () 2016 American Federation for Medical Research

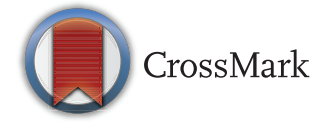

To cite: Grundy SM. J Investig Med 2016;64:1082-1086.

\section{ABSTRACT}

The metabolic syndrome is a constellation of metabolic risk factors including atherogenic dyslipidemia (elevated serum triglycerides, reduced high-density lipoprotein (HDL) cholesterol), elevated blood pressure, dysglycemia (insulin resistance and elevated serum glucose), a pro-inflammatory state, and a prothrombotic state. Most persons with metabolic syndrome are obese, and usually have abdominal obesity. Generally, obesity is a reflection of overnutrition. A current view is that when adipose tissue fails to store all excess nutrients as triglyceride, lipid begins to accumulate in various tissues (eg, muscle, liver, pancreas, and heart). This accumulation is called ectopic lipid. Various mechanisms have been proposed whereby ectopic lipid is detrimental in different tissues; these derangements induce metabolic risk factors. The foundation of the metabolic syndrome thus appears to be overnutrition, that is, more nutrient intake than can be safely disposed by lipid oxidation. Excess dietary carbohydrate also induces ectopic lipid. Of interest, less than half of obese individuals develop metabolic syndrome. Through various mechanisms they adapt to overnutrition so as to minimize lipid overload in tissues, and consequently, prevent the syndrome.

The metabolic syndrome is a constellation of metabolic risk factors including atherogenic dyslipidemia (elevated serum triglycerides, reduced high-density lipoprotein (HDL) cholesterol), elevated blood pressure, dysglycemia (insulin resistance and elevated serum glucose), a pro-inflammatory state and a prothrombotic state. ${ }^{1}{ }^{2}$ When present in combination, these factors essentially double the risk for atherosclerotic cardiovascular disease (ASCVD) $;^{3-5}$ they also increase risk for type 2 diabetes about fivefold. ${ }^{2}$ Most persons with metabolic syndrome are obese. This implies that overnutrition contributes to the syndrome. ${ }^{6}$ Still, less than half of obese individuals manifest multiple metabolic risk factors. ${ }^{7}$ Many persons seemingly are able to adapt to overnutrition so as to prevent the syndrome. The following discussion examines potential mechanisms underlying the metabolic syndrome and considers how the body defends against overload of nutrient energy.

The most plausible, unifying hypothesis for the pathogenesis of metabolic syndrome is that overnutrition drives accumulation of excess lipid in organs or tissues; this in turn deranges metabolic processes and predisposes to metabolic risk factors. ${ }^{6}$ Excess lipid in adipose tissue is called obesity; in other tissues, it is called ectopic lipid. In this document, overnutrition will be defined as the any excess of nutrient energy that causes ectopic lipid accumulation outside adipose tissue. The essential pathways whereby overnutrition drives development of ectopic lipid are shown in figure 1. Excess nutrients come from either dietary triglyceride or carbohydrate. Dietary triglyceride enters the circulation with chylomicrons. Triglycerides are hydrolyzed to fatty acids by lipoprotein lipase (LPL); and most of released fatty acids enter adipose tissue, where they are re-esterified to triglyceride. A portion of fatty acids released by LPL bypasses adipose tissue and enters a variety of tissues. Adipose tissue releases non-esterified fatty acids (NEFA), which pass into the circulation and likewise reach many tissues. Glucose derived from dietary carbohydrate goes directly into the same tissues. When excess glucose is consumed, it can be converted to fatty acids through a process known as lipogenesis. All carbohydrates and lipids are ultimately disposed by oxidation. At constant body weight, oxidation rates of triglyceride and carbohydrate equal their intakes, and lipid content of adipose tissue remains unchanged. An imbalance between intake and oxidation occurs only during periods of weight gain or loss. These facts are well known, but often are forgotten when the mechanisms for ectopic lipid and metabolic syndrome are discussed.

Whereas tissue overload by lipid predisposes to metabolic syndrome, and may be necessary for its development, it seemingly is not sufficient. Other factors, acting in local tissues, appear necessary for the clinical syndrome to present. The following briefly discusses the origins of ectopic lipid, and considers additional factors that bring out the syndrome.

\section{ADIPOSE TISSUE}

One emerging view holds that adipose tissue protects against accumulation of ectopic lipid and hence prevents metabolic syndrome through fat storage. ${ }^{8-11}$ If excess dietary nutrients could be stored fully in adipose tissue, ectopic lipid should not occur. Thus the metabolic syndrome may reflect insufficient adipose tissue to store the load of fat imposed upon it by a high-calorie diet. The best example of this mechanism is the rare condition called 


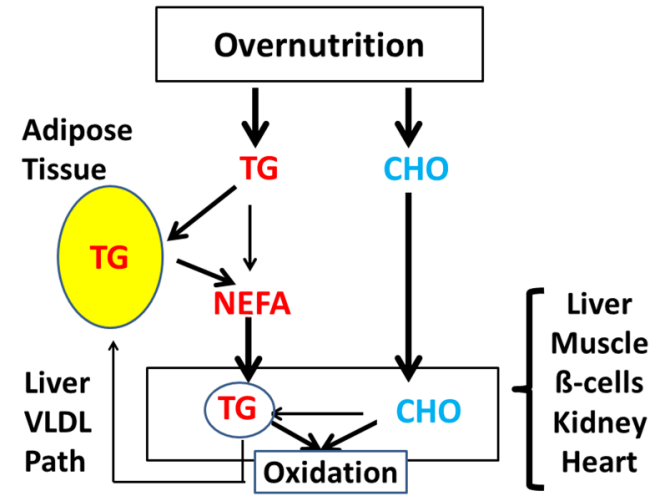

Figure 1 Major pathways for triglyceride (TG) and carbohydrate (CHO), in the form of glucose, derived from the diet. These pathways are described in detail in the text. NEFA, non-esterified fatty acids.

lipodystrophy. ${ }^{12} 13$ This is a condition of severe deficiency in adipose tissue; hence, consumed lipids cannot be adequately stored in adipose tissue and other tissues become overloaded. This precipitates the metabolic syndrome. Theoretically, even in the absence of lipodystrophy, the syndrome could occur if adipose tissue storage capacity is exceeded, even in the presence of clinical obesity.

Adipose tissue is the major site of uptake for lipid released during lipolysis of triglyceride-rich lipoproteins (TGRLP). These lipoproteins consist of chylomicrons, derived from dietary fat, and of very low-density lipoproteins (VLDL), produced by the liver. Fatty acids freed during lipolysis of TGRLP are taken up by adipose tissue and are re-esterified as triglycerides. In turn, adipose-tissue triglyceride undergoes lipolysis and releases NEFA into the circulation. During weight gain, fat storage is positive; at constant weight, no net storage of triglyceride occurs. NEFA release occurs mainly, but not exclusively, in the fasting state. Its release is regulated mainly by insulin. During fasting, when insulin levels are low, NEFA release is high; conversely, in the postprandial state, when insulin levels are high, NEFA release is suppressed. Thus, when excess calories are consumed, increased quantities of fatty acids cycle through adipose tissue.

Increased release of NEFA from adipose tissue in obese persons is commonly believed to be a cause of metabolic syndrome. Of course, high NEFA levels are the result of increased uptake of fatty acids by adipose tissue in response to overnutrition; elevated plasma NEFA therefore cannot be blamed on abnormalities in adipose tissue. For example, with caloric restriction, plasma NEFA levels rapidly decline despite persistent obesity. ${ }^{14}$ Indeed, fasting NEFA concentrations correlate relatively poorly with body-fat content. ${ }^{15}$ This finding likely reflects variability in caloric intake among individuals.

There are three adipose-tissue compartments that have been linked in various ways to metabolic syndrome. These are upper-body subcutaneous adipose tissue (UBSQ-AT), lower-body subcutaneous adipose tissue (LBSQ-AT) (gluteofemoral fat), and visceral adipose tissue (VAT). ${ }^{16} 17$ Upper-body fat, sometimes referred to as abdominal fat, actually includes all truncal fat, and represents the combination of UBSQ-AT and VAT compartments. Each adipose-tissue compartment can be discussed briefly relative to metabolic syndrome. Figure 2 shows apparent magnitudes of flow of fatty acids through these compartments.

Truncal adipose tissue correlates better with metabolic syndrome than does lower body adipose tissue. ${ }^{18-20}$ UBSQ-AT is the largest component of truncal adipose tissue. $^{21-23}$ It predominates in release of NEFA into the systemic and splanchnic circulations; ${ }^{21-23}$ thus UBSQ-AT could be a major source of ectopic lipid. Compared to LBSQ-AT, UBSQ-AT appears to be more insulin resistant; ${ }^{24-26}$ this means that UBSQ-AT more readily releases its fatty acids into the circulation, that is, it has higher turnover rates of fatty acids. ${ }^{27}$ Although UBSQ obesity is often implicated in causation of ectopic lipid, more likely, it just acts as a conduit for transfer of excess nutrient fatty acids to the circulation, as suggested in figure 1 .

A high VAT likewise has been strongly associated with metabolic syndrome. ${ }^{28-34}$ It is particularly correlated with hepatic ectopic lipid. ${ }^{35}$ Fatty acids entering the splanchnic circulation are destined for the liver. These can come from UBSQ-AT or directly from splanchnic lipolysis of TGRLP. ${ }^{36}$ Presumably, visceral obesity is a response to a greater flux of NEFA through the splanchnic bed.

Compared to upper body compartments, LBSQ-AT seems to possess a lower rate of turnover of fatty acids. Individuals with predominant lower body obesity have relatively normal plasma levels and turnover rates for NEFA. ${ }^{27}$ Lower body obesity has been postulated to be protective against the metabolic syndrome. ${ }^{37}$ More likely, it is relatively neutral, rather than being protective, because of its relatively low turnover rate for fatty acids. ${ }^{27}$

When obesity is present, adipose tissue becomes inflamed. This inflammation results from invasion by macrophages secondary to adipose-tissue dysfunction. ${ }^{38}$ Consequently, the adipose-tissue bed releases inflammatory cytokines and prothrombotic factors into the systemic circulation. Release of excess cytokines may induce a generalized proinflammatory state, which could contribute to both ASCVD $^{39}$ and diabetes. ${ }^{40}$ Release of prothrombotic factors may likewise predispose to acute ASCVD events. A host of other 'adipokines' has been identified. ${ }^{41}$ Whether these

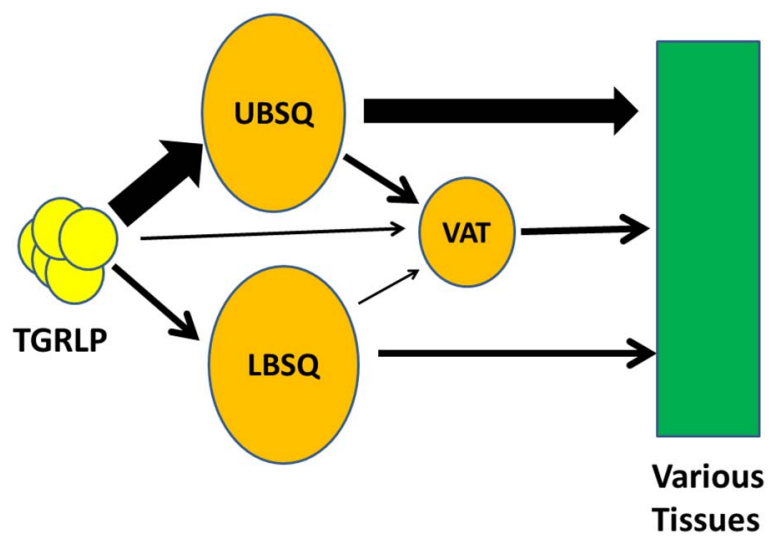

Figure 2 Pathways for fatty acids released by hydrolysis of triglyceride in triglyceride-rich lipoproteins (TGRLP). See text for details. Three major adipose tissue compartments are shown: upper body subcutaneous (UBSQ), lower body subcutaneous (LBSQ), and visceral (VAT). The size of the arrows reflects the magnitude of the flux through each pathway. 
participate in the relationship between obesity and metabolic syndrome remains to be determined.

\section{MUSCLE}

Overnutrition increases lean body mass as well as adiposetissue triglyceride. ${ }^{42} \mathrm{~A}$ greater lean body mass occurs in many tissues, but especially muscle. This results in greater energy expenditure, which should buffer against ectopic-lipid accumulation. When overnutrition induces high NEFA levels, muscle uptake of NEFA is enhanced. A greater muscle mass (and mitochondrial number), secondary to greater energy intake, defends against ectopic lipid. But imbalance between NEFA uptake and oxidation by muscle results in ectopic lipid and contributes to insulin resistance. ${ }^{43}$ The latter, of course, predisposes to hyperglycemia, an important metabolic risk factor.

\section{LIVER}

A high caloric intake increases the nutrient load on the liver. Like in muscle, high levels of fasting NEFA derived from adipose tissue raise hepatic uptake of fatty acids. As well, the liver has other sources of fatty acids. Among these are fatty acids released by lipolysis of TGRLP in the splanchnic circulation ${ }^{44}$ and hepatic uptake of chylomicron remnants. Further, when muscle is insulin resistant, more glucose is routed to the liver, which stimulates de novo synthesis of fatty acids. ${ }^{45}$ Thus, hepatic ectopic lipid in one way or another represents a product of overnutrition.

Ectopic lipid in the liver is synonymous with nonalcoholic fatty liver (NAFL). The latter in turn predisposes to non-alcoholic steatohepatitis, which can sometimes produce cirrhosis or liver cancer. NAFL occurs almost exclusively in obese persons; ${ }^{46}$ hence overnutrition is an underlying cause. But many obese individuals are able to avoid NAFL, ${ }^{46}$ presumably by incorporating excess lipid into VLDL or by enhancing fatty acid oxidation. Conversely, in some individuals, these two pathways are sluggish and trap fat in the liver. ${ }^{47}$

An increased load of fatty acids on the liver typically causes overproduction of VLDL particles. $^{48}$ Overproduction raises plasma triglycerides, provided they are not rapidly removed by enhanced lipolysis. ${ }^{48}$ An elevation in VLDL triglyceride is one important metabolic risk factor. Increased production of VLDL particles can further raise the plasma apolipoprotein $\mathrm{B}$-another lipoprotein risk factor. Finally, hepatic lipid overload stimulates the synthesis of hepatic lipase, ${ }^{49}$ an enzyme that degrades HDL particles and lowers HDL-cholesterol concentrations. Thus, an increased lipid load in the liver, which results from overnutrition, is the underlying cause of atherogenic dyslipidemia.

\section{KIDNEY}

Elevated blood pressure commonly occurs with the metabolic syndrome. Hyperinsulinemia is one factor implicated in causation of hypertension. ${ }^{50}$ Another contributor may be accumulation of ectopic lipid in the renal sinus and perinephric region. ${ }^{51}$ Renal sinus fat may compress venules and lymphatics in the kidney and thus impair blood pressure regulation. Moreover, excess lipid in the perinephric region may compress the kidneys, induce ischemia and cause hypertension. ${ }^{52}$

\section{PANCREAS}

Fatty acids as well as glucose stimulates insulin secretion. ${ }^{53-56}$ With overnutrition, excess fatty acids entering pancreatic $\beta$-cells likely are one cause of increased insulin secretion and hyperinsulinemia found in obese individuals. In accord, ectopic lipid has been observed in $\beta$-cells of obese, prediabetic animal models. ${ }^{57}$ Over time, ectopic lipid may destroy $\beta$-cells through overstimulation of insulin secretion and lipotoxiciy. ${ }^{58}$ The latter effect could account for the apparent insulin exhaustion' commonly observed in patients with type 2 diabetes. Of interest, MR spectroscopy shows that the pancreas contains ectopic lipid when diabetes is present, whereas it generally is absent when diabetes is not present. ${ }^{59}$

\section{HEART}

In many obese persons, ectopic lipid accumulation is found to occur in and around the heart. ${ }^{60}$ Several investigations suggest that lipid accumulation is detrimental to cardiac function (for a detailed review see reference). ${ }^{61}$

\section{CARBOHYDRATE OVERNUTRITION}

Most evidence supports the concept that fatty acids represent the final common pathway to tissue nutrient overload. Less attention has been given to the possible untoward effects of excessive intake of carbohydrate. For example, high-carbohydrate intakes enhance postprandial glycemia, which itself may be detrimental over the long run. Postprandial hyperglycemia may cause oxidative stress or otherwise be glucotoxic in a variety of tissues. ${ }^{62} 63$ Chronic overstimulation of insulin secretion induced by dietary carbohydrate could have at least two untoward effects. First, $\beta$-cell function may be impaired by chronic glucotoxicity; ${ }^{63-65}$ and second, carbohydrate-induced hyperinsulinemia may suppress muscle insulin sensitivity. ${ }^{66-68}$ Hyperinsulinemia associated with excess dietary carbohydrate may be secondary to fatty acids produced by lipogenesis in $\beta$-cells. Moreover, high-carbohydrate intakes can induce lipogenesis in the liver; ${ }^{69} 70$ fatty acids produced in this way can feed into the final common pathway of ectopic lipid accumulation (figure 1). Thus the role of carbohydrate overnutrition in the development of metabolic syndrome should not be overlooked. It is worthy of more investigation.

\section{OVERFEEDING STUDIES}

One approach to understanding the effects of overnutrition on the metabolic profile is through overfeeding studies. Many such studies have been carried out. ${ }^{71-76}$ They indicate that overnutrition produces a deterioration of metabolic status, although there is considerable individual variability in response. Such investigations are potentially useful for identifying those who are particularly susceptible the development of metabolic risk factors.

\section{GENETIC FACTORS}

The host of genetic factors likely act at tissue levels to influence the response to nutrient excess. Several genome-wide association studies have been carried out to search for genes contributing to the metabolic syndrome. ${ }^{77-80}$ These studies suggest that multiple different genes act simultaneously to modify metabolic risk factors. But occasionally, 
monogenic or oligogenic factors can predominate. In some cases, genetic abnormalities appear to predispose to ectopic lipid accumulation; in others, defects may elicit metabolic risk factors in those who already have ectopic lipid.

\section{THERAPEUTIC IMPLICATIONS Energy intake}

In obese individuals, caloric restriction is followed by loss of adipose-tissue triglyceride and diminished proinflammatory cytokines, prothrombotic factors and plasma NEFA. ${ }^{14} 8182$ With reduced calorie intake, muscle insulin resistance declines; hepatic steatosis diminishes; dyslipidemia frequently disappears; and blood pressure falls. As shown with bariatric surgery, all of these favorable changes occur long before substantial weight reduction takes place $^{83} 84$ These findings confirm that metabolic syndrome is driven largely by a high intake of nutrient energy. In the future, management of the metabolic syndrome should put priority on curbing caloric intake.

In the pharmacological arena, more emphasis needs to be placed on developing new agents that will safely reduce energy intake. This is because decreasing energy intake will treat all the metabolic risk factors at once. Research on the role of the hypothalamus in regulating energy appetite may uncover new avenues of therapy. ${ }^{85}$ But equally important is the need for public health measures to dampen overconsumption of nutrient energy. This can be better achieved through public education combined with edification of individuals at risk.

\section{Energy expenditure}

Ectopic fat results from an imbalance between energy intake and expenditure. A high caloric intake expands lean body mass and promotes energy expenditure; the latter helps to buffer ectopic lipid deposition. Nonetheless, in many people, expansion of lean body mass is insufficient to prevent ectopic lipid. The most obvious way to enhance energy expenditure is through greater physical activity. The ability of physical fitness and physical activity to reduce metabolic risk factors is well established. ${ }^{86}$ Some investigators speculate that tissue utilization of energy could be increased through pharmacological agents. To date this possibility has not been realized, but remains on the list of potential therapies for metabolic syndrome. Agents that could enhance nutrient oxidation should be particularly attractive.

\section{Management of individual metabolic risk factors}

Multiple cardiovascular risk factors can be treated individually with various drugs. ${ }^{87}$ Among these are drugs that favorably modify lipid levels, control blood pressure and reduce hyperglycemia. Antiplatelet drugs should decrease a prothrombotic state; aspirin for example is known to reduce cardiovascular events. Currently, anti-inflammatory drugs are being tested for efficacy to prevent atherosclerotic events. At present, in patients with metabolic syndrome, we must depend on polypharmacy for treatment of individual metabolic risk factors. ${ }^{87}$ Hopefully, the future will bring more effective interventions to modify caloric imbalance, which is the major driver of the syndrome.

\section{Competing interests None declared.}

Provenance and peer review Commissioned; externally peer reviewed.

\section{REFERENCES}

1 Grundy SM. Metabolic syndrome: a multiplex cardiovascular risk factor. J Clin Endocrinol Metab 2007;92:399-404.

2 Grundy SM, Cleeman JI, Daniels SR, et al. American Heart Association; National Heart, Lung, and Blood Institute. Diagnosis and management of the metabolic syndrome: an American Heart Association/National Heart, Lung, and Blood Institute Scientific Statement. Circulation 2005;112:2735-52.

$3 \mathrm{Hu} \mathrm{G}$, Qiao Q, Tuomilehto J, et al, DECODE Study Group. Prevalence of the metabolic syndrome and its relation to all-cause and cardiovascular mortality in nondiabetic European men and women. Arch Intern Med 2004;164:1066-76.

4 Gami AS, Witt BJ, Howard DE, et al. Metabolic syndrome and risk of incident cardiovascular events and death: a systematic review and meta-analysis of longitudinal studies. J Am Coll Cardiol 2007;49:403-14

5 Mottillo S, Filion KB, Genest J, et al. The metabolic syndrome and cardiovascular risk a systematic review and meta-analysis. J Am Coll Cardiol 2010;56:1113-32.

6 Grundy SM. Adipose tissue and metabolic syndrome: too much, too little or neither. Eur J Clin Invest 2015;45:1209-17.

7 Grundy SM, Neeland IJ, Turer AT, et al. Ethnic and gender susceptibility to metabolic risk. Metab Syndr Relat Disord 2014;12:110-16.

8 Wang $\mathrm{P}$, Mariman E, Renes J, et al. The secretory function of adipocytes in the physiology of White adipose tissue. J Cell Physiol 2008;216:3-13.

9 Manolopoulos KN, Karpe F, Frayn KN. Gluteofemoral body fat as a determinant of metabolic health. Int J Obes (Lond) 2010;34:949-59.

10 Krahmer N, Farese RV Jr, Walther TC. Balancing the fat: lipid droplets and human disease. EMBO Mol Med 2013;5:905-15.

11 Gustafson B, Hedjazifar S, Gogg S, et al. Insulin resistance and impaired adipogenesis. Trends Endocrinol Metab 2015;26:193-200.

12 Garg A, Misra A. Lipodystrophies: rare disorders causing metabolic syndrome. Endocrinol Metab Clin North Am 2004;33:305-31.

13 Huang-Doran I, Sleigh A, Rochford JJ, et al. Lipodystrophy: metabolic insights from a rare disorder. J Endocrinol 2010;207:245-55.

14 Thomas F, Smith GC, Lu J, et al. Differential acute impacts of sleeve gastrectomy, roux-en- $Y$ gastric bypass surgery and matched caloric restriction diet on insulin secretion, insulin effectiveness and non-esterified fatty acid levels among patients with type 2 diabetes. Obes Surg 2016 Published Online First: 4 Jan 2016. doi:10.1007/s11695-015-2038-3

15 Karpe F, Dickmann JR, Frayn KN. Fatty acids, obesity, and insulin resistance: time for a reevaluation. Diabetes 2011;60:2441-9.

16 Abate N, Burns D, Peshock RM, et al. Estimation of adipose tissue mass by magnetic resonance imaging: validation against dissection in human cadavers. J Lipid Res 1994;35:1490-6.

17 Vega GL, Adams-Huet B, Peshock R, et al. Influence of body fat content and distribution on variation in metabolic risk. J Clin Endocrinol Metab 2006;91:4459-66.

18 Bjorntorp P. Metabolic implications of body fat distribution. Diabetes Care 1991;14:1132-43.

19 Kissebah AH, Krakower GR. Regional adiposity and morbidity. Physiol Rev 1994;74:761-811.

20 Jensen MD. Role of body fat distribution and the metabolic complications of obesity. J Clin Endocrinol Metab 2008;93(Suppl 1):S57-63.

21 Guo ZK, Hensrud DD, Johnson CM, et al. Regional postprandial fatty acid metabolism in different obesity phenotypes. Diabetes 1999;48:1586-92.

22 Nielsen S, Guo ZK, Johnson CM, et al. Splanchnic lipolysis in human obesity. J Clin Invest 2004;113:1582-8.

23 Roust LR, Jensen MD. Postprandial free fatty acid kinetics are abnormal in upper body obesity. Diabetes 1993;42:1567-73.

24 Krotkiewski M, Björntorp P, Sjöström L, et al. Impact of obesity on metabolism in men and women. Importance of regional adipose tissue distribution. J Clin Invest 1983;72:1150-62.

25 Fried SK, Kral JG. Sex differences in regional distribution of fat cell size and lipoprotein lipase activity in morbidly obese patients. Int J Obes 1987;11:129-40.

26 Karastergiou K, Fried SK, Xie H, et al. Distinct developmental signatures of human abdominal and gluteal subcutaneous adipose tissue depots. J Clin Endocrinol Metab 2013;98:362-71.

27 Jensen MD, Haymond MW, Rizza RA, et al. Influence of body fat istribution on free fatty acid metabolism in obesity. J Clin Invest 1989;83:1168-73.

28 Björntorp P. Visceral obesity: a "civilization syndrome". Obes Res 1993;1:206-22.

29 Cefalu WT, Wang ZQ, Webel S, et al. Contribution of visceral fat mass to the insulin resistance of aging. Metabolism 1995;44:954-9. 
30 Seidell JC, Bjorntorp P, Sjostrom L, et al. Visceral fat accumulation in men is positively associated with insulin, glucose, and C-peptide levels, but negatively with testosterone levels. Metabolism 1990;39:897-901.

31 Kuk JL, Katzmarzyk PT, Nichaman MZ, et al. Visceral fat is an independent predictor of all-cause mortality in men. Obesity 2006;14:336-42.

32 Matsuzawa Y, Funahashi T, Nakamura T. The concept of metabolic syndrome: contribution of visceral fat accumulation and its molecular mechanism. J Atheroscler Thromb 2011;18:629-39.

33 Tchernof A, Després JP. Pathophysiology of human visceral obesity: an update. Physiol Rev 2013;93:359-404

34 Abate N, Garg A, Peshock RM, et al. Relationships of generalized and regional adiposity to insulin sensitivity in men. J Clin Invest 1995;96:88-98.

35 Guerrero R, Vega GL, Grundy SM, et al. Ethnic differences in hepatic steatosis: an insulin resistance paradox? Hepatology 2009;49:791-801.

36 Nelson RH, Basu R, Johnson CM, et al. Splanchnic spillover of extracellular lipase-generated fatty acids in overweight and obese humans. Diabetes 2007;56:2878-84

37 Karpe F, Pinnick KE. Biology of upper-body and lower-body adipose tissuelink to whole-body phenotypes. Nat Rev Endocrinol 2015;11:90-100.

38 Weisberg SP, McCann D, Desai M, et al. Obesity is associated with macrophage accumulation in adipose tissue. J Clin Invest 2003:112:1796-808.

39 Willerson JT, Ridker PM. Inflammation as a cardiovascular risk factor. Circulation 2004;109(Suppl 1):112-10.

40 Glass CK, Olefsky JM. Inflammation and lipid signaling in the etiology of insulin resistance. Cell Metab 2012;15:635-45.

41 Lehr S, Hartwig S, Sell H. Adipokines: a treasure trove for the discovery of biomarkers for metabolic disorders. Proteomics Clin App/ 2012;6:91-10.

42 Lillioja S, Bogardus C. Obesity and insulin resistance: lessons learned from the Pima Indians. Diabetes Metab Rev 1988;4:517-40.

43 Shulman Gl. Ectopic fat in insulin resistance, dyslipidemia, and cardiometabolic disease. N Engl J Med 2014;371:2237-8.

44 Donnelly $\mathrm{KL}$, Smith Cl, Schwarzenberg SJ, et al. Sources of fatty acids stored in liver and secreted via lipoproteins in patients with nonalcoholic fatty liver disease. J Clin Invest 2005;115:1343-51.

45 Flannery C, Dufour S, Rabøl R, et al. Skeletal muscle insulin resistance promotes increased hepatic de novo lipogenesis, hyperlipidemia, and hepatic steatosis in the elderly. Diabetes 2012;61:2711-17.

46 Vega GL, Chandalia M, Szczepaniak LS, et al. Metabolic correlates of nonalcoholic fatty liver in women and men. Hepatology 2007;46:716-22.

47 Romeo S, Kozlitina J, Xing C, et al. Genetic variation in PNPLA3 confers susceptibility to nonalcoholic fatty liver disease. Nat Genet 2008;40:1461-5.

48 Grundy SM, Mok HY, Zech L, et al. Transport of very low density lipoprotein triglycerides in varying degrees of obesity and hypertriglyceridemia. J Clin Invest 1979;63:1274-83.

49 Nie L, Wang J, Clark LT, et al. Body mass index and hepatic lipase gene (LIPC) polymorphism jointly influence postheparin plasma hepatic lipase activity. J Lipid Res 1998;39:1127-30.

50 Rao A, Pandya V, Whaley-Connell A. Obesity and insulin resistance in resistant hypertension: implications for the kidney. Adv Chronic Kidney Dis 2015:22:211-17.

51 Foster MC, Hwang SJ, Porter SA, et al. Fatty kidney, hypertension, and chronic kidney disease: the Framingham Heart Study. Hypertension 2011;58:784-90.

52 Hall JE. Pathophysiology of obesity hypertension. Curr Hypertens Rep 2000;2:139-47

53 Stein DT, Esser V, Stevenson BE, et al. Essentiality of circulating fatty acids for glucose-stimulated insulin secretion in the fasted rat. J Clin Invest 1996;97:2728-35.

54 Dobbins RL, Chester MW, Daniels MB, et al. Circulating fatty acids are essential for efficient glucose-stimulated insulin secretion after prolonged fasting in humans. Diabetes 1998;47:1613-18.

55 Dobbins RL, Chester MW, Stevenson BE, et al. A fatty acid- dependent step is critically important for both glucose- and non-glucose-stimulated insulin secretion. J Clin Invest 1998;101:2370-6.

56 Boden $\mathrm{G}$, Chen $\mathrm{X}$, Iqbal N. Acute lowering of plasma fatty acids lowers basal insulin secretion in diabetic and nondiabetic subjects. Diabetes 1998;47:1609-12.

57 Unger RH, Zhou YT. Lipotoxicity of beta-cells in obesity and in other causes of fatty acid spillover. Diabetes 2001;50(Suppl 1):S118-21.

58 Shimabukuro M, Zhou YT, Levi M, et al. Fatty acid-induced beta cell apoptosis: a link between obesity and diabetes. Proc Natl Acad Sci USA 1998;95:2498-502.

59 Szczepaniak LS, Victor RG, Mathur R, et al. Pancreatic steatosis and its relationship to $\beta$-cell dysfunction in humans: racial and ethnic variations. Diabetes Care 2012:35:2377-83.
60 McGavock JM, Victor RG, Unger RH, et al. American College of Physicians and the American Physiological Society. Adiposity of the heart, revisited. Ann Intern Med 2006;144:517-24.

61 lacobellis G, Corradi D, Sharma AM. Epicardial adipose tissue: anatomic, biomolecular and clinical relationships with the heart. Nat Clin Pract Cardiovasc Med 2005;2:536-43.

62 von Bibra H, St John Sutton M, Schuster T, et al. Oxidative stress after a carbohydrate meal contributes to the deterioration of diastolic cardiac function in nonhypertensive insulin-treated patients with moderately well controlled type 2 diabetes. Horm Metab Res 2013;45:449-55.

63 Unger RH, Grundy S. Hyperglycaemia as an inducer as well as a consequence of impaired islet cell function and insulin resistance: implications for the management of diabetes. Diabetologia 1985;28:119-21.

64 Zimmet $P$, Dowse $G$, Bennett $P$. Hyperinsulinaemia is a predictor of non-insulin-dependent diabetes mellitus. Diabete Metab 1991;17(Pt 2):101-8.

65 Poitout V, Robertson RP. Glucolipotoxicity: fuel excess and beta-cell dysfunction. Endocr Rev 2008;29:351-66

66 Rizza RA, Mandarino LJ, Genest J, et al. Production of insulin resistance by hyperinsulinaemia in man. Diabetologia 1985;28:70-5.

67 Kahn BB, Flier JS. Obesity and insulin resistance. J Clin Invest 2000;106:473-81.

68 Marín-Juez R, Jong-Raadsen S, Yang S, et al. Hyperinsulinemia induces insulin resistance and immune suppression via Ptpn6/Shp1 in zebrafish. J Endocrinol 2014;222:229-41.

69 Hudgins LC, Baday A, Hellerstein MK, et al. The effect of dietary carbohydrate on genes for fatty acid synthase and inflammatory cytokines in adipose tissues from lean and obese subjects. J Nutr Biochem 2008;19:237-4.

70 Chong MF, Hodson L, Bickerton AS, et al. Parallel activation of de novo lipogenesis and stearoyl-CoA desaturase activity after $3 \mathrm{~d}$ of high-carbohydrate feeding. Am J Clin Nutr 2008;87:817-23.

71 Forbes GB, Brown MR, Welle SL, et al. Deliberate overfeeding in women and men; energy cost and composition of the weight gain. $\mathrm{Br}$ / Nutr 1986;56:I-9.

72 Samocha-Bonet D, Campbell LV, Viardot A, et al. A family history of type 2 diabetes increases risk factors associated with overfeeding. Diabetologia. 2010;53:1700-8.

73 Diaz EO, Prentice AM, Goldberg GR, et al. Metabolic response to experimental overfeeding in lean and overweight healthy volunteers. Am J Clin Nutr 1992:56:641-55.

74 McDevitt RM, Bott SJ, Harding M, et al. De novo lipogenesis during controlled overfeeding with sucrose or glucose in lean and obese women. Am J Clin Nutr 2001;74:737-46.

75 Ravussin E, Schutz Y, Acheson KJ, et al. Short term mixed diet overfeeding in man: no evidence for "luxuskonsumption". Am I Physiol 1985;249:E470-7.

76 Wulan SN, Westerterp KR, Plasqui G. Metabolic profile before and after short-term overfeeding with a high-fat diet: a comparison between South Asian and White men. Br J Nutr 2014:111:1853-61.

77 Stirnadel $\mathrm{H}$, Lin $\mathrm{X}$, Ling $\mathrm{H}$, et al. Genetic and phenotypic architecture of metabolic syndrome-associated components in dyslipidemic and normolipidemic subjects: the GEMS Study. Atherosclerosis 2008;197:868-76.

78 Fall T, Ingelsson E. Genome-wide association studies of obesity and metabolic syndrome. Mol Cell Endocrinol 2014;382:740-57.

79 Norris JM, Rich SS. Genetics of glucose homeostasis: implications for insulin resistance and metabolic syndrome. Arterioscler Thromb Vasc Biol 2012;32:2091-6.

80 Rankinen T, Sarzynski MA, Ghosh $\mathrm{S}$, et al. Are there genetic paths common to obesity, cardiovascular disease outcomes, and cardiovascular risk factors? Circ Res 2015;116:909-22.

81 Le T, Flatt SW, Natarajan L, et al. Effects of Diet Composition and Insulin Resistance Status on Plasma Lipid Levels in a Weight Loss Intervention in Women. J Am Heart Assoc 2016;25:5.

82 Miller GD, Isom S, Morgan TM, et al. Effects of a community-based weight loss intervention on adipose tissue circulating factors. Diabetes Metab Syndr 2014;8:205-11.

83 Buchwald $\mathrm{H}$, Avidor $\mathrm{Y}$, Braunwald $\mathrm{E}$, et al. Bariatric surgery: a systematic review and meta-analysis. JAMA 2004;292:1724-37.

84 Clifton PM. Bariatric surgery: results in obesity and effects on metabolic parameters. Curr Opin Lipidol 2011;22:1-5.

85 Gautron L, Elmquist JK, Williams KW. Neural control of energy balance: translating circuits to therapies. Cell 2015;161:133-45.

86 Grundy SM, Barlow CE, Farrell SW, et al. Cardiorespiratory fitness and metabolic risk. Am J Cardiol 2012;109:988-93.

87 Grundy SM. Drug therapy of the metabolic syndrome: minimizing the emerging crisis in polypharmacy. Nat Rev Drug Discov 2006;5:295-309. 